\title{
Optimal reconstruction of water supply network under conditions of reduced water consumption
}

\author{
Roman V. Chupin ${ }^{1}$, Minh Ngoc Pham ${ }^{2 *}$, Viktor R. Chupin ${ }^{1}$ \\ ${ }^{1}$ Irkutsk National Research Technical University,83 Lermontov St., Irkutsk 664074, Russia \\ ${ }^{2}$ Vinh University,182 Le Duan St., Vinh, Vietnam
}

\begin{abstract}
In recent years, due to the country's energy conservation policies in cities and towns, there has been a steady decline in the specific water consumption. Many industrial enterprises switched to water-saving technologies and circulating water supply systems. Such a policy favorably affects the environmental safety of territories by reducing wastewater discharges into water bodies and saves energy for pumping water and wastewater. At the same time, due to a decrease in the speed of water movement, its quality indicators deteriorate and stagnant zones appear, and due to the reduction of water consumption, pumping stations began to operate in low efficiency modes. The article proposes to solve this problem by decommissioning certain sections of the network and facilities, which improve the speed of other pipelines and provide pumping stations with the highest efficiency. For this purpose, a technique has been developed to optimize flows in existing water supply systems and its implementation in the Trace - BK software package. A new method of optimizing operating costs for water supply systems in the face of decreasing water consumption is proposed. This technique makes it possible to identify inefficient sections of network and take them out of operation while improving the operation speed of other pipeline and bring the operation of pumping stations to the mode with the highest efficiency.
\end{abstract}

\section{Introduction}

Under the conditions of developed socialism, it was believed that the more the urban population consumes water, the greater the degree of improvement. This philosophy contributed to the growth of specific water consumption, including its irrational component. By 2000 , the average water consumption in the country was $4001 /$ person per day, and by cities and towns, it reached 800 or more. Taking into account the growing water consumption, the project norms increased, and for the development of the feasibility study stage they reached 500-600 1/person per day and on the basis of them, new pipelines, pumping stations, sewage treatment plants were designed and constructed. Since 2000 , the specific water consumption began to decrease. The reasons for this were the following factors:

- Rationalization of water consumption;

- Transition to water-saving technologies;

* Corresponding author: minhrow@gmail.com 
- Introduction of circulating water use systems;

- Liquidation of water-intensive technologies and enterprises;

Rationalization of water consumption has become one of the main components in the state policy in the field of energy and resource conservation. It is enshrined in the Federal Law-261 "On energy saving and on improving energy efficiency ...". In many cities water consumption decreases by $3-5 \%$ annually. And in the near future it will be 150 liters per person. per day, i.e. decrease 2.5 times.

This situation has a positive effect on the efficiency of water use in the industrial and residential sectors. This significantly reduces the cost of electricity for pumping water, reduces the amount of wastewater. However, negative factors appear that lead to an increase in operating costs. These factors are as follows: 1) by reducing the speed of water movement in water supply systems, stagnant zones appear, leading to deterioration of water quality and its freezing in the winter period, sediment deposits increase for wastewater systems and pipeline overgrowth occurs, leading to an increase in internal corrosivity; 2) by reducing the flow of water and wastewater, existing pumping stations operate in inefficient modes with low efficiency, even if they are equipped with an adjustable electric drive; 3) the concentration of wastewater has increased significantly, which for many WWTP led to the violation of technological regimes and demanded additional costs for reagents and the reorganization of individual facilities.

A more difficult situation is observed in the industry, especially in enterprises that used huge water resources in their technology and in recent years have switched to waterless and circulating water supply systems (chemical, petrochemical, nuclear, machine building and other industries). Thousands of kilometers of network and structures have stopped working or are operating in non-optimal and non-rational modes of operation. At the same time for these reasons, operating costs increase, which is reflected in the cost of production.

It is proposed to solve this problem by decommissioning certain sections of the system and facilities, which improve the speed of other pipelines and provide pumping stations with the highest efficiency. The only question is what areas and facilities should be decommissioned. For this purpose, we investigate operating costs and determine the effect on them of regime parameters of water supply systems.

\section{Methods}

The aggregate operating costs for water supply systems are calculated as follows $[1,2,3,4]$ :

$$
E_{z}=C_{a m}+C_{k . r}+C_{t . r}+C_{e l c}+C_{f z p}+C_{s v}+C_{n . v}+C_{p r},
$$

where $E_{z}$ - annual operating costs (thousand rubles/year); $C_{a m}$ depreciation deductions (equal to $0.05 * \mathrm{~K}$ for pipelines, $0.09 * \mathrm{~K}$ for pumping stations and surface water intake, $0.14 * \mathrm{~K}$ for wells and underground water intakes, $\mathrm{K}$ - one-time investment in the water supply system); $C_{k . r}$ major repairs costs $(0.046 * K)$, rubbles/year; $C_{t . r}$ the cost of maintenance $(0.01 * \mathrm{~K})$, rubles/year; $C_{e l c}$ electricity cost, thousand rubles/year:

$$
\mathrm{C}_{e l c}=108 \cdot \mathrm{z}_{e} \cdot \mathrm{H} \cdot \mathrm{x}
$$

where $z_{e}$ is the unit cost of electricity (rubles per $\mathrm{kWh}$ ), $\mathrm{x}$ - transported water consumption $\left(\mathrm{m}^{3} / \mathrm{s}\right) \mathrm{H}$ - pressure of pumping station, $C_{f z p}$ staff salary fund per $1 \mathrm{~km}$ length of the pipeline:

$$
C_{f z p}=0,75 \cdot Z P_{s r} \cdot x^{0,3},
$$

where $Z P_{s r}$ average forecasted salary by the enterprise, thousand rubles/month; $x$ - system performance, in $\mathrm{m}^{3} / \mathrm{s} ; C_{s v}-$ consists of insurance contributions to the pension fund 
$\left(0.22 * C_{f z p}\right)$, social insurance fund $\left(0.029 * C_{f z p}\right)$ and the health insurance fund $\left(0.051 * C_{f z p}\right)$; $C_{n . v}$ - water tax (thousand rubles/year) is determined by:

$$
\mathrm{C}_{\mathrm{n} . \mathrm{v}}=31536 \cdot \mathrm{C}_{\mathrm{n} . \mathrm{st}} \cdot \mathrm{x} \text {, }
$$

where $C_{n . s t}$ tax rate in rubles for $1 \mathrm{~m}^{3}$ of water withdrawn from surface and underground sources (in Irkutsk in 2018 this rate is 0.122 rubles per $1 \mathrm{~m}^{3}$ ); $C_{p r}$-other expenses, thousand rubles/year, are taken in $20 \%$ of depreciation deductions $\left(C_{a m}\right)$ and salary costs for staff $\left(C_{f z p}\right)$,

$$
C_{p r}=0,2 \cdot\left(C_{a m}+C_{f z p}\right) \text {, или } C_{p r}=0,01 \cdot K+0,15 \cdot Z P_{s r} \cdot x^{0,3} \text {. }
$$

Taking into account (2)-(3) operating costs will be as follows:

$$
E_{z}=0,116 \cdot K+C_{e l c}+1,125 \cdot Z P_{s r} \cdot x^{0,3}+31536 \cdot C_{n . s t} \cdot x .
$$

To specify one-time (capital investment) costs, we use the information given in the enlarged standards of construction prices $[5,6]$. For external water supply networks of $1 \mathrm{~km}$ in length from polyethylene pipes, when dry soil working to a depth of $3 \mathrm{~m}$ (which is typical for the Irkutsk Region), it is not difficult to obtain the following dependence of investments on the diameter of the pipeline:

$$
K=\left(27329 \cdot d^{2}+7399,5 \cdot d+2537,9\right) \cdot L,
$$

where $\mathrm{K}$ - capital investment (thousand rubles), $\mathrm{d}$ - diameter (m), Which can be represented as a function of $\mathrm{v}-$ speed in $\mathrm{m} / \mathrm{s}$ and $\mathrm{x}-$ flow in $\mathrm{m}^{3} / \mathrm{s}$

$$
d=\sqrt{\frac{4 x}{\pi v}},
$$

Taking into account (6):

$$
\mathrm{K}=\left(34796,4 \cdot \mathrm{x} \cdot \mathrm{v}^{-1}+8346,6 \cdot \mathrm{x}^{0,5} \cdot \mathrm{v}^{-0,5}+2537,9\right) \cdot \mathrm{L}
$$

The calculation of electricity costs requires separate consideration. In the theory of hydraulic circuits [7],the law of conservation of energy for an arbitrary hydraulic circuit is formulated as follows: "All the energy introduced, minus the energy for the outflow of water, is spent on overcoming friction forces":

$$
\sum_{j=1}^{J_{1}} Q_{j} \cdot H_{j}-\sum_{j=1}^{J_{2}} Q_{j} \cdot P_{j}=\sum_{i=1}^{n} h_{i} \cdot x_{i},
$$

where $J_{1}$ - set of pumping stations nodes , $J_{2}$ - set of water consumption nodes, $H_{j}-$ piezometric water pressure of pumping stations, $P_{j}$ - piezometric water pressure at consumers (m), $h_{i}$ - pressure loss over water supply network sections, $x_{i}$ - flow of water transported by network sections, $Q_{j}$ - water consumption at consumer $j, \mathrm{~m}^{3} / \mathrm{s}$.

Therefore, the annual cost of electricity for the water supply system can be represented as the sum of the electricity cost for each section in network:

$$
C_{\text {elc }}=108 \cdot Z_{\text {elc }} \cdot E_{i}, \quad E_{i}=h_{i} \cdot x_{i},
$$

To calculate the pressure loss along the length of the pipeline, we use the formula F.A. Sheveleva for plastic pipes [8]: 


$$
h_{i}=1,1 \cdot y_{i} \cdot L_{i}, Y_{i}=0,001052 \cdot \frac{x_{i}^{1,774}}{d_{i}^{4,774}},
$$

цhere $Y_{i}$ - hydraulic slope, $L_{i}$ - the length of the network section (m).

$$
h_{i} \cdot x_{i}=0,0011572 \cdot L_{i} \cdot \frac{x_{i}^{2,774}}{d_{i}^{4,774}}
$$

or taking into account (6):

$$
\begin{gathered}
h_{i} \cdot x_{i}=0,000642 \cdot L_{i} \cdot x_{i}^{0,378} \cdot v_{i}^{2,387} . \\
C_{\text {elc }}=108 \cdot Z_{\text {elc }} \cdot\left(0,000642 \cdot x_{i}^{0,387} \cdot v_{i}^{2,387} \cdot L_{i} \cdot 1000\right), L \text { in } \mathrm{km} .
\end{gathered}
$$

As a result, we obtained dependencies of operating costs as a function of the water flow and speed of the transported water, the length of the pipeline and the unit cost of electricity.

$$
\begin{aligned}
& E_{z}=0,116 \cdot \mathrm{K}+108 \cdot Z_{\text {elc }} \cdot\left(0,000642 \cdot x_{i}^{0,387} \cdot v_{i}^{2,387} \cdot L_{i} \cdot 1000\right)+ \\
& 1,125 \cdot \mathrm{ZP}_{\mathrm{sr}} \cdot \mathrm{x}^{0,3}+31536 \cdot \mathrm{C}_{\mathrm{n} . \mathrm{st}} \cdot \mathrm{x}
\end{aligned}
$$

The dependence of operating costs on the flow rate and water velocity in the pipeline, as well as their linear approximations $C_{e}=C \cdot x$ are shown in Figure 1.
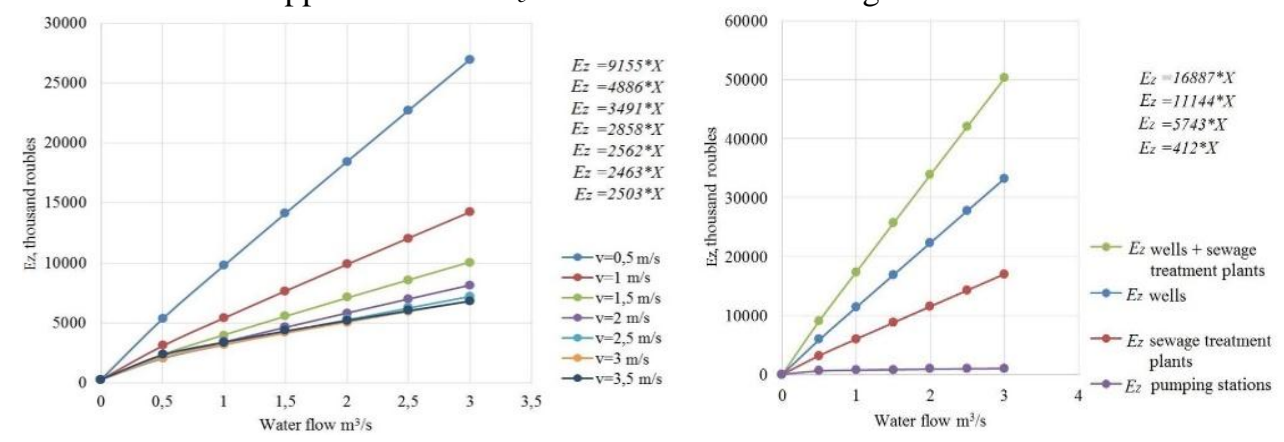

Fig. 1. The dependence of operating costs on the flow and speed of water in the pipeline

Taking into account the obtained dependencies, we can formulate a mathematical formulation of the problem of minimizing operating costs in existing water supply systems as the task of finding the maximum flow of the minimum cost [16]:

$$
\sum_{i=1}^{n} C_{i} \cdot K_{o b, i} \cdot x_{i} \rightarrow \min , \text { with } \underline{B}_{i} \leq x_{i} \leq \bar{B}_{i}, A \cdot x=q_{c p}^{\prime},
$$

where $n$ - the number of network sections, $C_{i}-$ the cost of a flow unit. For example, at a speed of $3 \mathrm{~m} / \mathrm{s}, \mathrm{C}=2463.0$ thousand rubles for $1 \mathrm{~m}^{3} / \mathrm{s}$ per $1 \mathrm{~km}$ length; for the device of the underground water intake with water treatment plants (removal of hardness and iron) $\mathrm{C}=$ 16887.0 thousand rubles for $1 \mathrm{~m}^{3} / \mathrm{s}$; for pumping stations $\mathrm{C}=412.0$ thousand rubles for 1 $\mathrm{m}^{3} / \mathrm{s} ; K_{o b, I}-$ the overall coefficient of unevenness in the network section i, obtained on the basis of actual or forecast water consumption graphs; $x_{i}$ - target flow on a branch of a redundant or transport network; $\underset{=i}{\sigma},{ }_{B_{i}}$ - lower and upper limits on flow $x_{i} ; A$ - connection matrix of nodes and network branches; $q_{c p}$ - vector of average of water consumption, $\mathrm{m}^{3} / \mathrm{s}$. 
To solve this problem, this paper proposes the following methodology, based on the works $[17-19,21]$ : 1) a mathematical model of the existing water supply network is being formed, its adequacy is checked on the basis of hydraulic calculations [22], operating costs are determined, pipeline sections with speeding violations are identified; 2) based on the model of the existing water supply system, we will build a transportation network. To build it, all the water consuming nodes are closed using fictitious branches to the common node $t$ - the flow output, and the water source nodes are closed to the common fictitious node of the flow entrance S. At the same time, for each section of the transport network, restrictions are imposed on their carrying capacity (upper and lower). For fictitious flow entry branches, the upper limits correspond to the maximum possible performance of water intakes or a secondlift pumping station, and for fictitious flow exit branches, the upper limits correspond to the human settlements needs in water. The upper limit on the flow of the existing network sections is determined based on the optimal values of the water velocity:

$$
\bar{B}=V_{o p t} \cdot \frac{\pi \cdot d^{2}}{4}
$$

The lower limit is assigned according to SP 31.13330.2012 "Water supply. External networks and facilities ", but not less than $0.7 \mathrm{~m} / \mathrm{s}$. For each network segment, the cost of the flow unit is determined - the operating costs of the flow unit: 1) taking into account the constructed transport network, the task of finding the maximum flow of the minimum cost is solved (10),(11); 2) as a result, solutions will be determined sections on which the flow will not pass. These sections and require decommissioning.

\section{Results and discussion}

As an example, consider an industrial water supply system that supplies water to technological workshops (see Fig. 2a). The total capacity is $0.14 \mathrm{~m}^{3} / \mathrm{s}$. Hydraulic calculation showed that there are no speed violations in the network. Operating costs amount to 40,495.0 thousand rubles/year. In 2020, it is planned to transfer eight workshops to the circulating water supply. As a result of optimization, 12 network sections were removed, which are shown in Fig. $2 \mathrm{~b}$ are shown in thin lines. For the remaining network, operating costs amounted to 9172.0 thousand rubles/year, which is 31323.0 thousand rubles/year less than if the network sections were not withdrawn to the reserve.

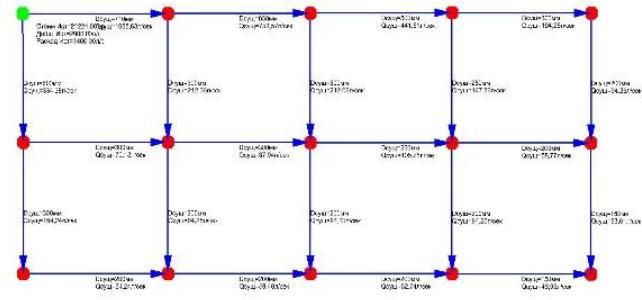

a)

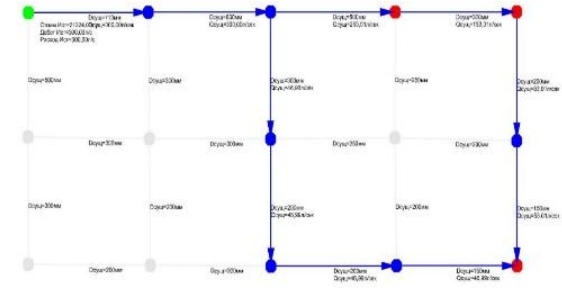

b)

Fig. 2. Scheme of the existing water supply system and calculation results

\section{Conclusions}

We proposed a new method of optimizing operating costs for water supply systems under conditions of decreasing water consumption. This technique allows to identify inefficient sections of the network take them out of operation while improving the speed of other 
pipeline sections and bring the operation of pumping stations to the highest efficiency. This tethodology and software complex [20] is an effective tool for justification the network structure and facilities of water supply systems under conditions of decreasing and increasing water consumption. They can be useful for decision makers to optimize the technological structure of the enterprise and a perspective scheme for the development of urban areas.

\section{References}

1. B.N. Repin, Water supply and drainage. External systems and facilities (High School, Moscow, 1995)

2. Order of the RF Gosstroy from 03.22.1999, №66.

3. Typical standards 001 dated 24.01.2014 (The Russian Federation Ministry of Labor)

4. Z. G. Lyubanskaya, P.P. Osipov, Economy of water supply and drainage systems. (Pacific Publishing House State University, Khabarovsk, 2012)

5. NSC 81-02-14-2017. Collection No. 14. Update: 01.01.2018

6. NSC 81-02-19-2017

7. A.P. Merenkov, V.Ya. Khasilev, Theory of hydraulic circuits (Science, Moscow, 1985)

8. F.A. Shevelev, Tables for the hydraulic calculation of steel, cast iron, asbestos cement, plastic and glass water pipes (Stroyizdat, Moscow, 1973)

9. V.I. Bazhenov, E.I. Pupyrev, G.A. Sambursky, S.E. Berezin, Water supply and sanitary engineering, 2, 10 (2018)

10. Franninga Lars and others. The cost of the life cycle of the pump (Hydraulic Institute. Brussels, Belgium, 2001)

11. E.S. Gogina, A.D. Gurinovich, Water supply and sanitary equipment, 9, 36 (2016)

12. Preparation of the technical and economic part of projects of off-site water supply and sewage systems. Reference Guide to SniP (Stroyizdat, Moscow, 1991)

13. Order No 1746-e of the Federal Tariff Service of Russia dated December 27, 2013.

14. Order No 99of the Russian Federation Ministry of Regional Development of October 10, 2007

15. Economics of water supply and sanitation: a manual for the study of the discipline and for the independent work of full-time students (VolGU, Vologda, 2013)

16. N. Christofides, Graph Theory. Algorithmic approach (Mir, Moscow, 1978)

17. R.V. Chupin, Optimization of developing wastewater systems (ISTU, Irkutsk, 2015)

18. R.V. Chupin, V.R. Chupin, Pham Ngoc Minh, E.A. Gorkov, M.V. Moroz, Proceedings of Universities: Investment. Construction. Real estate, 8(2), 94 (2008)

19. R.V. Chupin, I.V. Meisel, Proceedings of Universities: Investment. Construction. Real estate, 1(4), 126 (2003)

20. E.S. Melekhov, V.R. Chupin, R.V. Chupin, Certificate of state registration of the computer program №2016615463 TRACE-VR dated May 25, 2016 1990)

21. E. Mushik, P. Muller. Techniques for making technical decisions, (Mir, Moscow,

22. R.V. Chupin, E.S. Melehov, The development of the theory and practice of modeling and optimization of water supply and wastewater systems (ISTU, Irkutsk, 2011) 